\title{
Letter from the Editor-in-Chief
}

I am happy to announce that the AIB Executive Board has approved a new $J I B S$ policy concerning photocopying. We hereby grant blanket permission to photocopy material published in JIBS if that material is to be used for non-profit purposes. This permission covers tables, charts, and full-length articles, as well as multiple copies of an article.

A major goal of JIBS is to disseminate the research efforts of our authors and to make their work as widely available as possible to professors and students. We believe that this new photocopying policy will effectively further this end.

In granting this permission, we require no notice and we expect no fee. However, please note that permission is still necessary (and fees are usually charged) for JIBS material which is to be published elsewhere or used for profit-oriented activities by individuals or organizations.

David A. Ricks 